\title{
Diabetic Kidney Disease: Challenges, Advances, and Opportunities
}

\author{
Ya Chen ${ }^{a, b}$ Kyung Lee ${ }^{a}$ Zhaohui $\mathrm{Ni}^{\mathrm{b}}$ John Cijiang He ${ }^{\mathrm{a}}$ \\ a Department of Medicine/Nephrology, Icahn School of Medicine at Mount Sinai, New York, NY, USA; \\ ${ }^{\mathrm{b}}$ Department of Nephrology, Ren Ji Hospital, School of Medicine, Shanghai Jiao Tong University, Shanghai, China
}

\section{Keywords}

Diabetic kidney disease - Progression - Nonproteinuric pathway · Inflammation $\cdot$ Treatment

\begin{abstract}
Background: Diabetic kidney disease (DKD) is the most common cause of the end-stage renal disease (ESRD). Regardless of intensive treatments with hyperglycemic control, blood pressure control, and the use of renin-angiotensin system blockades, the prevalence of DKD remains high. Recent studies suggest that the spectrum of DKD has been changed and many progresses have been made to develop new treatments for DKD. Therefore, it is time to perform a systemic review on the new developments in the field of DKD. Summary: Although the classic clinical presentation of DKD is characterized by a slow progression from microalbuminuria to macroalbuminuria and by a hyperfiltration at the early stage and progressive decline of renal function at the late stage, recent epidemiological studies suggest that DKD patients have a variety of clinical presentations and progression rates to ESRD. Some DKD patients have a decline in renal function without albuminuria but display prominent vascular and interstitial fibrosis on renal histology. DKD patients are more susceptible to acute kidney injury, which might
\end{abstract}

contribute to the interstitial fibrosis. A large portion of type 2 diabetic patients with albuminuria could have overlapping nondiabetic glomerular disease, and therefore, kidney biopsy is required for differential diagnosis for these patients. Only a small portion of DKD patients eventually progress to end-stage renal failure. However, we do not have sensitive and specific biomarkers to identify these high-risk patients. Genetic factors that have a strong association with DKD progression have not been identified yet. A combination of circulating tumor necrosis factor receptor (TNFR) 1, TNFR2, and kidney injury molecular 1 provides predictive value for DKD progression. Artificial intelligence could enhance the predictive values for DKD progression by combining the clinical parameters and biological markers. Sodium-glucose cotransporter- 2 inhibitors should be added to the new standard care of DKD patients. Several promising new drugs are in clinical trials. Key Messages: Over last years, our understanding of DKD has been much improved and new treatments to halt the progression of DKD are coming. However, better diagnostic tools, predictive markers, and treatment options are still urgently needed to help us to better manage these patients with this detrimental disease.

\section{(c) 2020 The Author(s)}

Published by S. Karger AG, Basel

\begin{tabular}{ll}
\hline karger@karger.com & (c) 2020 The Author(s) \\
Published by S. Karger AG, Basel Oparger & Koen ciccess \\
www.karger.com/kdd & This article is licensed under the Creative Commons Attribution- \\
Karger & NonCommercial-NoDerivatives 4.0 International License (CC BY- \\
NC-ND) (http://www.karger.com/Services/OpenAccessLicense). \\
Usage and distribution for commercial purposes as well as any dis- \\
tribution of modified material requires written permission.
\end{tabular}

John Cijiang He, MD, PhD

Department of Medicine/Nephrology, Icahn School of Medicine at Mount Sinai One Gustave L Levy Place, Box 1243

New York, NY 10029 (USA)

cijiang.he@mssm.edu 


\section{Introduction}

Diabetic kidney disease (DKD) remains as the most common cause of end-stage renal disease (ESRD) in US and most countries. In recent years, the spectrum of DKD has been evolved. Our understanding of DKD pathogenesis has been also advanced significantly. Sodium-glucose co-transporter-2 (SGLT2) inhibitors have been approved as new drugs to treat patients with DKD. In addition, several new drugs have been in clinical trials with some success. Therefore, we believe that it is the time to write this review to update the current understanding of clinical manifestations, disease progression, pathological changes, and management of DKD patients in the new era.

\section{Good and Bad News in the DKD Epidemiology}

Diabetes affects 30.3 million people of all ages representing $9.4 \%$ of US population [1] and about 149 million people and $10.9 \%$ of the population in China [2] and 415 million worldwide [3]. DKD is the most common cause of the ESRD in the world, and it is associated with increased morbidity and mortality in diabetic patients [4]. Although the incidence rate of chronic kidney disease (CKD) in diabetic patients has decreased in recent years in the US, the prevalence remains high. In 2018, USRDS annual data reported that diabetes accounted for $36 \%$ of CKD in the NHANES population between 2013 and 2016, declining from $44 \%$ between 2001 and 2004. However, due to the increased number of diabetic patients, the total number of DKD patients was further increased. The numbers of diabetic adults aged over 18 years who began treatments for ESRD also increased significantly from over 40,000 in 2000 to over 50,000 in 2014 [5]. In China, both the incidence and prevalence of DKD have risen dramatically over the last decade. In China Kidney Disease Network 2015 annual data report, DKD is the primary cause of CKD, accounting for $26.96 \%$ [6]. The estimated number of diabetic patients with CKD in China reached 24.3 million [7]. Therefore, DKD is a global public health burden.

\section{Albuminuria Is Not Necessarily Associated with a Decline in Glomerular Filtration Rate in DKD}

Typical clinical manifestations of DKD include albuminuria, which progresses to macroalbuminuria or overt proteinuria over time, microscopic hematuria, which presents only in a small portion of patients, and a low progression rate of renal function. Classically, DKD is divided into 5 stages. The stages 1 and 2 are preclinical stages, characterized by an increase of glomerular filtration rate (GFR), normoalbuminuria (stage 1) or intermittent microalbuminuria (MA; stage 2 ), and normal blood pressure. Stage 3 is the onset of clinical stage, characterized by persistent MA, mild hypertension, and a normal or slight decline in GFR. Stage 4 is characterized by macroalbuminuria, hypertension, and further decline of GFR. Stage 5 is the end stage of renal disease.

However, recent epidemiological studies suggest that not all patients with DKD follow the above classification, particularly in patients with type 2 diabetes mellitus (DM). Growing evidence suggests that proteinuria does not always occur preceding the loss of renal function in diabetes, which contradicts the abovementioned conventional progression of DKD [8-10]. In some patients, the progression of DKD to ESRD may occur without a transition from MA to overt proteinuria. Perkins et al. [11] reported that the early decline of GFR occurs in a large proportion of patients with only MA. In addition, the decline of GFR without albuminuria (nonproteinuric DKD) has been increasingly recognized, especially in type 2 diabetes [12-16]. Kramer et al. [17] reported that renal insufficiency occurs in the absence of albuminuria and retinopathy among adults with type 2 DM. Population-based studies from western countries suggest that about half of individuals with a decline of kidney function did not have preceding proteinuria or never progressed to proteinuria in type 2 diabetes [18]. Compared with proteinuric $\mathrm{DKD}$, nonproteinuric DKD revealed a weaker association with diabetic retinopathy [19]. All the findings may suggest a nonalbuminuric pathway for the progression of $\mathrm{DKD}$. The overview of DKD is seen in Figure 1.

\section{Identification of High-Risk DKD Patients}

DKD is a chronic, progressive disease that develops over time. In the 1970s, the median time to ESRD from the development of overt proteinuria in type I diabetes was 7 years [20] and now is 14 years [21]. The incidence of ESRD in type I diabetes from Finland is now $7.8 \%$ at 30 years duration [22]. Much evidence has shown that many patients who are well treated may have relatively stable kidney function or progression at a very slow rate. In 3 recent randomized interventional studies, the rate of decline of eGFR ranged from 0 to $4 \mathrm{~mL} / \mathrm{min}$ per year [2325]. A major factor that may contribute to progression to 
Fig. 1. Overview of DKD. DKD, diabetic kidney disease, ACEI, angiotensin-converting enzyme inhibitor; ARB, angiotensin II receptor blocker; SGLT2, sodiumglucose cotransporter 2; eGFR, estimated glomerular filtration rate; $\mathrm{BP}$, blood pressure.

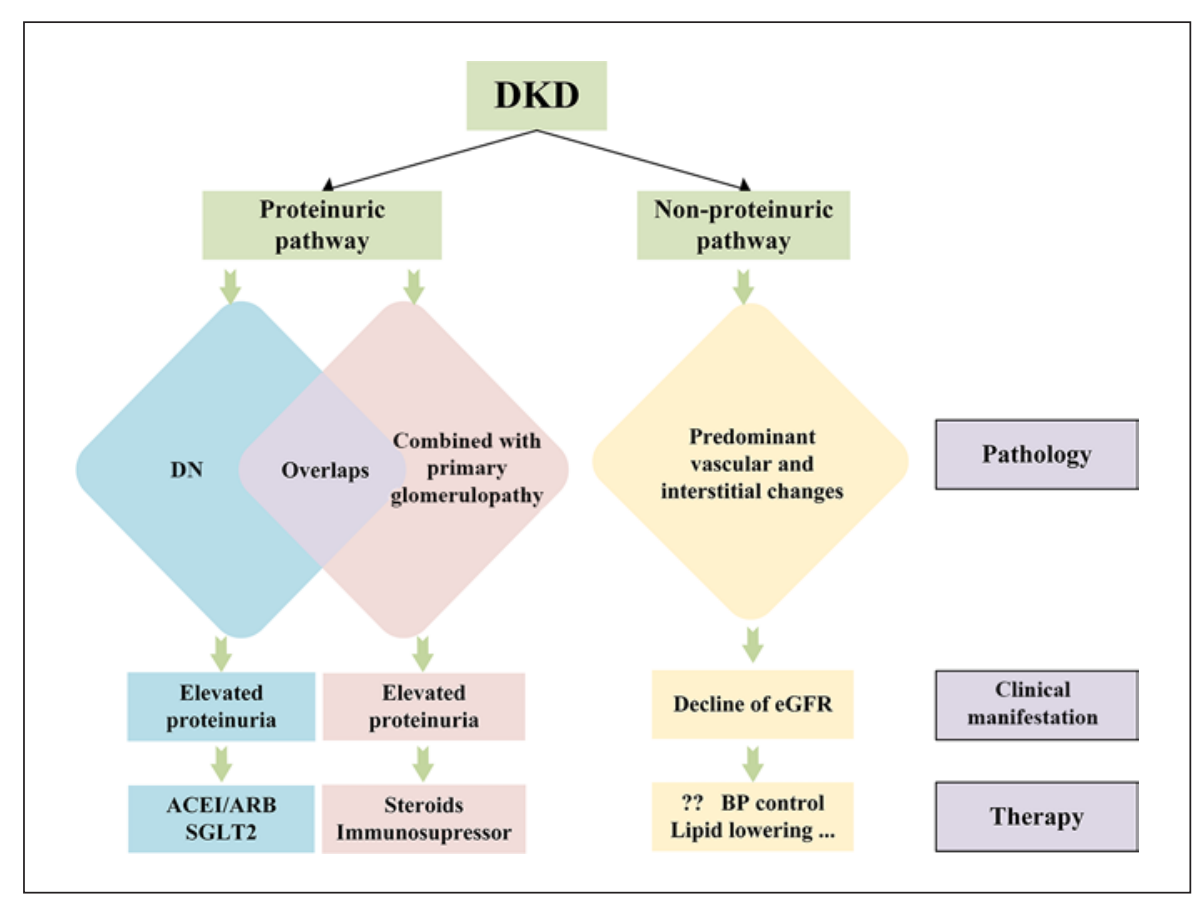

ESRD in patients with diabetes is acute kidney injury (AKI). Thakar et al. [26] demonstrated that, in a cohort of 4,082 patients with diabetes, single or repetitive episodes of AKI significantly increase the risk of developing advanced CKD. Subsequently, a large prospective study further confirmed that AKI itself can also predict major adverse outcomes including doubling of serum creatinine or ESRD in patients with diabetes [27]. Results of the latest research are in line with the above; they found that AKI events were associated with progression to renal replacement rate and also with a greater severity of subsequent AKI [28]. This may explain why some DKD patients have an early decline of GFR with a minimal amount of albuminuria.

Not all DKD patients have identical progression rates. In general, about one-third of patients will progress to MA in 15-20 years after the diagnosis of diabetes and normoalbuminuria. One-third of patients with MA do not progress after treatments, but another one-third of them will deteriorate to macroalbuminuria within 10 years. In the next 10 years, one-third of those with macroalbuminuria will develop to ESRD. Only one-third of the ESRD patients will be still alive in the following 5 years. Since the progression rate is so different among individual patients with DKD, we need to develop new biomarkers that allow us to predict the progression rate of GFR at the early stage of DKD. When patients of all types of diabetes have been included, the incidence rate of ESRD has been 1-9 per 1,000 patient-years [29-32]. In type I diabetes patients, the cumulative risk of ESRD and the incidence of renal replacement rate have decreased markedly during the past 5 decades [33] but that is not obvious in type 2 diabetes patients [34]. Risk for developing ESRD over 20 years in type 2 diabetes patients is about $2 \%$. Studies suggest that intensive glycemic control did not reduce significantly clinical renal end points, including doubling of serum creatinine, ESRD, and death from renal disease in type $2 \mathrm{DM}$ [35]. Many studies have been undertaken to develop the biomarkers for early detection of these high-risk DKD patients. MA is a dynamic marker at the early stage of DKD and therefore could not be used to predict the progression of DKD [36]. In addition, progression of DKD is not necessarily associated with proteinuria, and thus, proteinuria is also not a sensitive marker for DKD progression. Although intensive glycemic control is able to reduce nephropathy in both type 1 [37] and type 2 diabetes [38], hemoglobin A1c at the early stage of $\mathrm{DKD}$ does not predict the late progression of DKD [39]. As for kidney pathology, structural predictors of loss of renal function in American Indians with type 2 diabetes include mean glomerular volume, glomerular basement membrane (GBM) width, mesangial fractional volume per glomerulus, glomerular filtration surface density, nonpodocyte number per glomerulus, foot pro- 
cess width, podocyte detachment, and endothelial fenestration [40]. However, it is unusual to perform kidney biopsy at early DKD. In addition, an autopsy study suggests that histological findings do not necessary correlate with clinical presentation in diabetic patients [41]. Searching for genetic factors is another important approach. Unfortunately, none of the genetic factors have been found to have a strong association with the progression of DKD. Family Investigation of Nephropathy and Diabetes Research Group recently reported that no genome region showed linkage across all ethnic groups. The Genetics of Kidneys in Diabetes (GoKind) study showed no single major gene that contributes to an increased risk of diabetic nephropathy (DN) emerged from the analysis of their data [42]. APOL1 risk allele, which is highly implicated in African-American nondiabetic kidney disease with an odds ratio of $>10$, is only weakly associated with DKD. Many groups have investigated blood and urine biomarkers for DKD progression based on the pathogenesis of the disease such as cytokines and growth factors. Serum markers include soluble tumor necrosis factor receptor a (TNFa) receptors, TNFa, interleukin 6 (IL-6) neutrophil gelatinase-associated lipocalin, IL-18 and Ltype fatty acid-binding protein of tubular cell injury, serum endothelial nitric oxide synthase, von Willebrand factor and vascular endothelial growth factor, and kidney injury molecular 1 (KIM-1). Urine markers include IL-6, IL-18, monocyte chemoattractant protein-1 (MCP-1) of inflammation, transforming growth factor- $\beta$ (TGF- $\beta$ ), connective tissue growth factor, isoprostanes and 8-hydroxy-2'-deoxyguanosine, podocyte number or expression of podocyte markers, IV collagen of GBM, YKL-40 (also known as chitinase 3-like 1), and MCP-1 [43]. So far, the best circulating biomarkers that could predict the progression of DKD are tumor necrosis factor receptor (TNFR)1, TNFR2, and KIM-1. Gohda et al. [44] found that circulating TNF receptors 1 and 2 predict the progression to stage $3 \mathrm{CKD}$ in type 1 diabetes. Elevated concentrations of circulating TNFRs in patients with type 2 diabetes at baseline are very strong predictors of the subsequent progression to ESRD in subjects with and without proteinuria [45]. TNFR but not hemoglobin A1c predicts that the progression of CKD may imply the possibility that DKD is an inflammatory disease, which could explain why hyperglycemic control is not enough to control the disease progression. Fornoni et al. [97] investigated the role of local and systemic TNF in podocyte injury and implied a nuclear factor of activated T cells 1/ ATP-binding cassette transporter A1-dependent mechanism through which local TNF is sufficient to cause free cholesterol-dependent podocyte injury irrespective of TNF, TNFR1, or TNFR2 serum levels [46]. Further researches are in need to clarify how activation of circulating TNF pathway contributes to DKD. In addition, KIM1 level at baseline was observed strongly predicted rate of eGFR loss and ESRD during 5-15 years of follow-up in a cohort of patients with type 1 diabetes and proteinuria [44]. This suggests that tubular cell injury occurred early at $\mathrm{DKD}$ and was associated with the progression. Coca et al. [47] combined those biomarkers and demonstrated 3-plex biomarker panel (plasma TNFR1, TNFR2, and KIM-1) aided risk-stratification for renal end points (sustained $40 \%$ decline in eGFR or ESRD) in type 2 diabetics. In the future, artificial intelligence could be applied to combine clinical parameters with the circulating biomarkers to enhance the predictive value for DKD progression. Identification of such a diagnostic tool will help us to better manage the patients with the early stages of DKD. This includes lifestyle modification, resource allocation, and the use of medications. The progression and related biomarkers of DKD are seen in Figure 2.

\section{New Insights into DKD Pathology}

$\mathrm{DN}$ is classically characterized by GBM thickening, mesangial expansion, nodular glomerular sclerosis, and tubulointerstitial fibrosis [48]. The traditional paradigm of glomerulus-centered pathophysiology has expanded to the tubule-interstitium and the immune response [49]. In type 1 diabetes patients, Mauer et al. [50-52] reported that the thickening of GBM is the earliest structural finding occurring in 1.5-2.5 years after the diagnosis of DM and the mesangial expansion with matrix deposition occurred in 5-7 years after diagnosis of DM. In later stages, afferent and efferent arteriolar hyalinosis and Kimmelstiel-Wilson nodules are seen, both of which are considered specific findings of DN. Simultaneously, tubular basement thickening, parallel to GBM thickening, is also observed. As for type 2 diabetes, the pathological changes are more complicated and often classified into 3 categories [53]: class I is the classic diabetic glomerulopathy as described above; class II has predominant vascular and interstitial changes, relatively normal glomerular structure. This group of patients often has an early decline of GFR without significant albuminuria. Clinically, patients have an early decline of GFR without significant proteinuria. Mechanistically, these patients may have unrecognized AKI episodes during the disease progression. Class III is divided into 2 subclasses: IIIa is another glomerular 
Fig. 2. Progression and biomarkers of DKD. KIM-1, kidney injury molecular 1; TNFR, tumor necrosis factor receptor; GBM, glomerular basement membrane; eGFR, estimated glomerular filtration rate; KW, Kimmelstiel-Wilson; ESRD, endstage renal disease; MA, microalbuminuria.

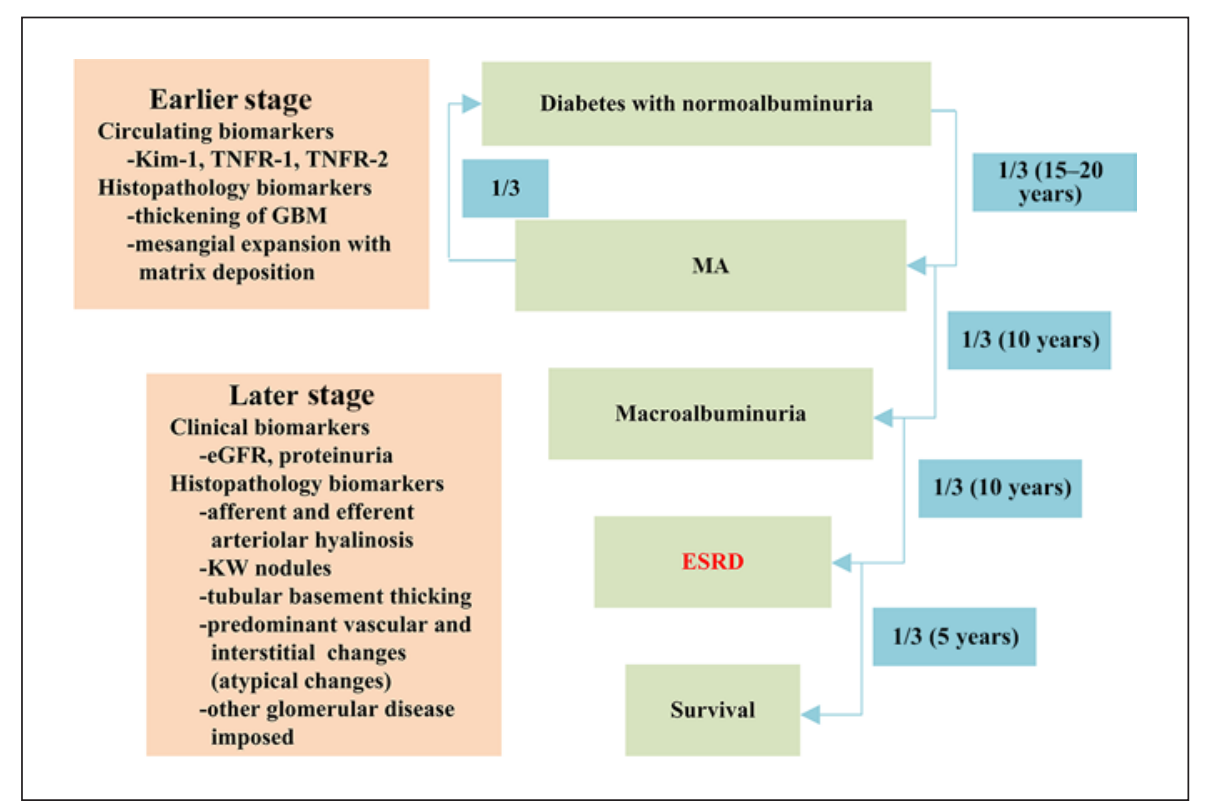

disease superimposed on diabetic glomerular structure (accounting for 19\%) and IIIb is non-DKD glomerular disease (with no changes of GBM and mesangial expansion, accounting for $18 \%$ ). This class accounts for a total of $50 \%$ of DKD patients. It is unclear whether diabetes interacts with the primary glomerular disease to accelerate the progression of CKD.

In type 1 diabetes, most patients could have a diagnosis of DKD based on clinical presentation. However, the diagnosis of DKD in type 2 diabetes often requires additional tests including kidney biopsy. Diabetes is a common disease with high coincidence with other nondiabetic CKD. Another interesting observation is that clinical manifestation is not necessarily associated with histological findings in $\mathrm{DKD}$, as suggested by an autopsy study [41]. In that research, 106 of 168 patients had histopathologic changes of DN in the kidney, but 20 of 106 histologically proven $\mathrm{DN}$ cases did not present with $\mathrm{DN}$ associated clinical manifestations within their lifetime. At the most clinical practice, patients with atypical clinical features should prompt evaluation for non-DKD by performing kidney biopsy. These atypical presentations are constructed of rapidly decreasing renal function, rapidly increasing proteinuria, active urinary sediment, refractory hypertension, and nephrotic range of proteinuria with normal GFR. Since the generalized vascular disease is common in diabetes, refractory hypertension and/or a severe drop of GFR after renin-angiotensin system (RAS) blockade should prompt consideration of renal artery ste-

DKD: Challenges, Advances, and

Opportunities nosis. Membranous diseases or minimal change disease should be ruled out from a nephrotic range of proteinuria with normal GFR because these patients could be treated with steroids and immunosuppressive therapy. However, since almost $50 \%$ of diabetic patients could have nonDKD glomerular diseases or other glomerular diseases overlapped with $\mathrm{DKD}$, we would suggest that any type 2 DM patients with significant proteinuria should undergo kidney biopsy to rule out these conditions.

\section{Challenges and Opportunities in Developing New Therapies for DKD}

Conventional therapy of DKD includes better hyperglycemic control, RAS blockers, and other managements such as lipid-lowering therapy and so on. In humans, RAS inhibition has proved to be the single most effective therapy for slowing the progression of DN [54]. However, 3 randomized, placebo-controlled trials of $256-3,326$ patients with type 1 diabetes and normoalbuminuria (RASS [55], EUCLID [56], AND DIRECT [57]) suggest that early therapy in patients, type 1 diabetes is ineffective in preventing the development of MA. In addition, the combination therapy with an angiotensin-converting enzyme inhibitor plus an angiotensin II receptor blocker does not prevent renal disease progression or death, and it increases the rate of serious adverse events such as AKI, hyperkalemia, and hypotension, as shown by the Veterans Af- 
fairs Nephropathy in Diabetes study (VA NEPHRON-D) [58]. The continued increase in diabetic ESRD urgently requires additional innovative therapies. A better understanding of the pathogenesis of DKD could help us to identify new drug targets for DKD.

\section{Newly Approved Drugs for DKD Treatment}

The recent success of SGLT2 inhibitors as a new therapy for DKD patients is exciting and encouraging news for the nephrologists. SGLT2 normally accounts for approximately $90 \%$ of glucose reabsorption in the renal proximal tubule [59], and its inhibitors are used in type $2 \mathrm{DM}$ to treat hyperglycemia by increasing glucose excretion in the urine. SGLT2 inhibitors have been shown to lower body weight, blood pressure, serum uric acid, and glomerular hyperfiltration through increased urinary excretion of glucose and sodium, osmotic diuresis, and improved tubule-glomerular feedback mechanism [60]. In Cherney's study (NCT01392560), they found that short-term treatment with empagliflozin, an SGLT2 inhibitor, attenuated renal hyperfiltration in subjects with type 1 diabetes [61]. In patients with type $2 \mathrm{DM}$ and high cardiovascular risks, empagliflozin is associated with slower progression of kidney disease and lower rates of clinically relevant renal events than placebo when added to standard care $[62,63]$. Canagliflozin, another SGLT2 inhibitor, was shown in patients with type 2 diabetes and kidney disease (CREDENCE); the risk of kidney failure was significantly lower in the canagliflozin group than in the placebo group at a median follow-up of 2.62 years [64]. Compared with glimepiride, canagliflozin 100 or $300 \mathrm{mg}$ /day slowed the progression of renal disease over 2 years in patients with type 2 diabetes, and it may confer renoprotective effects independently of its glycemic effects [65]. In Dekkers research, they demonstrated that 6 weeks of dapagliflozin decreased albuminuria by $43.9 \%$ and eGFR by $5.1(2.0-8.1)$ $\mathrm{mL} / \mathrm{min} / 1.73 \mathrm{~m}^{2}$ compared to placebo [66]. In another study (NCT02413398), in patients with type 2 diabetes and CKD 3A, decreases from baseline in eGFR were greater with dapagliflozin than placebo at Week 24 $\left(-2.49 \mathrm{~mL} / \mathrm{min} / 1.73 \mathrm{~m}^{2}[-4.96\right.$ to -0.02$\left.]\right)$; however, eGFR returned to baseline levels at Week 27 [67]. Based on these studies, SGLT2 inhibitors have been approved to treat DKD patients with eGFR $>45 \mathrm{~mL} / \mathrm{min}$, and therefore, SGLT2 inhibitors should be included as part of standard therapy for patients with DKD. However, attentions should be paid to side effects such as hypoglycemia, urinary and genital infections, elevated liver enzymes, bone fractures, or amputations.
Promising Drugs in Phase III Clinical Trials for DKD

\section{Treatment}

Glucagon-like peptide-1 (GLP-1) is one of the incretins released from the intestine in response to food intake and it can stimulate insulin secretion. Its level is decreased and its analogs (e.g. liraglutide) have been used in type $2 \mathrm{DM}$. According to the Liraglutide Effect and Action in Diabetes: Evaluation of Cardiovascular Outcomes Results double-blind trial with 9,340 patients with type $2 \mathrm{DM}$ and high cardiovascular risk, patients with liraglutide had lower rate of new onset of persistent macroalbuminuria and progression of DKD than placebo $[68,69]$. In another randomized study of 3,297 patients with type 2 diabetes, patients using semaglutide (another GLP-1 analog) had lower rates of new or deteriorating nephropathy than those with placebo [70]. Dipeptidyl peptidase 4 inhibitors linagliptin and saxagliptin can reduce the amount of albuminuria, but the evidence is less clear than GLP-1 analog [71, 72]. Peroxisome proliferator activated receptor- $\gamma$ agonist, rosiglitazone, can significantly decrease urinary albumin to creatinine ratio in type 2 diabetes patients after 3 months of therapy [73]. In Agarwal's research, though pioglitazone group had a reduction of $7.2 \%$ proteinuria, it was not statistically significant [74]. Avosentan, an endothelin-1 receptor A antagonist, can reduce urinary albumin excretion, but the study was terminated early because of excessive cardiovascular events during the treatment course due to the fluid overload [75]. A recent study in 211 patients showed that atrasentan, a more selective endothelin receptor A antagonist, had a proteinuria-lowering effect without significant accumulation of body fluid [76]. However, this study was terminated early due to the recruitment issue. Future studies are required to confirm whether atrasentan has additional renal protective effects on top of the RAS blockades and SGLT2 inhibitors, the new standard care for DKD patients. Mineralocorticoid receptor antagonists (MRA) exert an antifibrotic and antiinflammatory effect on the kidneys and other target organs like the heart and vessels [77]. Due to significant side effects associated with the first- (spironolactone) and second- (eplerenone) generation MRA, new MRA such as apararenone (also called MT-3995), esaxerenone, and finerenone have a relatively low risk of hyperkalemia. A clinical trial of MT-3995 in patients with DKD (NCT02676401) is ongoing in Japan (clinicaltrials.gov). Esaxerenone is also being studied in phase II and III randomized clinical trial (RCT), but no results have been published yet [78]. Finerenone has been investigated in several phase II RCTs. In the MRA tolerability study- 
heart failure (ARTS-HF), finerenone reduced albuminuria in patients with CKD and heart failure and had a lower risk of hyperkalemia than spironolactone [79]. In the more recent ARTS-DN study in patients with type 2 diabetes, macroalbuminuria, and eGFR $=$ or $<60 \mathrm{~mL} /$ min per $1.73 \mathrm{~m}^{2}$, finerenone reduced albuminuria in a dose-dependent manner. The risk of hyperkalemia leading to discontinuation was $2.1,3.2$, and $1.7 \%$ in the finerenone $7.5,15$, and $20 \mathrm{mg} /$ day groups, respectively [80]. Two double-blind placebo-controlled phase III RCTs, FIDELIO (NCT02540993) and FIGARO (NCT 02545049) are currently ongoing to examine the effects of finerenone on DKD and cardiovascular outcomes [81, 82]. Pirfenidone, an oral nonspecific antifibrotic agent, was shown to have a mean increase of eGFR after 1 year of therapy in $1,200 \mathrm{mg} /$ day group in a randomized, double-blind, placebo-controlled study with 77 DKD subjects [24]. Another phase III RCT (NCT02689778) to determine the effect of pirfenidone on GFR and albuminuria in patients with DKD is still ongoing. Pentoxifylline, another nonspecific antifibrotic agent, was shown to reduce albuminuria and slow progression of renal disease in patients with type 2 diabetes with stages 3-4 CKD on top of RAS blockade [83]. Two more clinical trials (NCT03625648 and NCT03664414) are ongoing.

\section{Potential Drugs Required Further Validations}

Hyperglycemia-associated generation of advanced glycation end products (AGE) and engagement of the receptor for AGE with its ligands can induce oxidative stress and renal inflammation. Pyridoxamine, a member of family of vitamin B6, can remove free radicals and carbonyl products and block synthesis of AGEs. Clinical studies showed that pyridoxamine did not provide a significant renal protection in DKD patients [84], but a significant beneficial effect was observed in a subgroup of DKD population. Therefore, more clinical studies are required to further confirm this finding. Systems biology approach reveals that both NF-kB and Janus kinase (JAK)/signal transducer and activator of transcription pathway are heavily involved in the pathogenesis of DKD. Not only in immune cells, but JAK-signal transducer and activator of transcription also play critical roles in renal cells, including mesangial cells, podocytes, and tubular epithelial cells [85]. This pathway is activated by reactive oxygen species induced by the hyperglycemic state [86]. A phase II clinical trial using Baricitinib, a selective JAK1 and JAK-2 inhibitor, showed a reduction of proteinuria and expression of several inflammatory markers in patients with DKD [85]. Nuclear factor-2 erythroid related

DKD: Challenges, Advances, and

Opportunities factor (Nrf2)-keep 1 pathway has been also shown to play a major role in the progression of DKD [87]. Pharmacological activation of Nrf2 decreases cytokine production, M1 macrophage accumulation, and the formation of an atherosclerotic plaque lipid core in the experimental model of streptozotocin-induced diabetic mice on an apolipoprotein E-deficient background [88]. In addition, its activation improves the pathological changes in the glomerulus of streptozotocin-induced diabetic mice through a reduction in oxidative stress, TGF- $\beta$ expression, and extracellular matrix proteins [89]. Bardoxolone methyl reduces the generation of oxidative stress by the activation of Nrf2 and inhibition of NF-kB pathway. The short-term study revealed that the use of bardoxolone methyl can increase the GFR in patients with type 2 DM and impaired renal function but have no influence of albuminuria [23]. However, the large phase III clinical study was terminated early because of more cardiovascular events [90]. Oxidative stress plays a critical role in the pathogenesis of DN [91]. NADPH oxidase (NOX) enzyme isoforms are involved in the production of reactive oxygen species that cause kidney cell injury in DKD [92]. GKT137831, a NOX1/4 inhibitor, has been shown to have a beneficial effect in murine models of DN [92]. However, the phase II trial in patients with T2DM and albuminuria failed to show any significant renal protection [93]. APX115 , a pan-NOX inhibitor, has been shown to have a renal protective effect in an experimental animal model of diabetes [94], but human studies have not been done yet. The proinflammatory chemokine ligand 2, also known as MCP-1, has been implicated in the pathogenesis of DN and has become a novel treatment target. Mouse models treated with NOX-E36, a chemokine ligand 2 inhibitor, exhibited a reduction in albuminuria [95]. A phase II clinical trial demonstrated that treatment of NOX-E36 reduced albuminuria in patients with T2DM and DN [96]. Long-term effects of these medications on renal outcomes and mortality are still in need. All drugs for DKD treatment are shown in Table 1.

\section{Conclusion}

DKD remains the most common cause of ESRD in the world including the US and China. DM patients with CKD could have a variety of clinical presentations with or without albuminuria. We need to perform more kidney biopsy for DKD patients with albuminuria because a significant number of DM patients could have non-DKD glomerular disease. The clinical presentation does not 
Table 1. Review of drugs for DKD treatments

\begin{tabular}{|c|c|c|c|}
\hline Categories & Drugs & Studies & Outcomes/status \\
\hline \multicolumn{4}{|c|}{ Newly approved drugs } \\
\hline \multirow[t]{6}{*}{ SGLT2 inhibitor } & \multirow[t]{2}{*}{ Empagliflozin } & $\begin{array}{l}\text { NCT01392560 } \\
\text { (clinicaltrials.gov) }\end{array}$ & $\begin{array}{l}\text { Attenuate renal hyperfiltration in subjects with type } 1 \\
\text { diabetes }\end{array}$ \\
\hline & & Wanner et al. [63], 2016 & Slower progression of kidney disease \\
\hline & \multirow[t]{2}{*}{ Canagliflozin } & Perkovic et al. [64], 2019 & Significantly lower risk of kidney failure \\
\hline & & Heerspink et al. [65], 2017 & $\begin{array}{l}\text { Slower the progression of renal disease over } 2 \text { years in } \\
\text { type } 2 \text { diabetes }\end{array}$ \\
\hline & \multirow[t]{2}{*}{ Dapagliflozin } & Dekkers et al. [66], 2018 & $\begin{array}{l}6 \text { weeks of dapagliflozin decrease albuminuria and } \\
\text { eGFR }\end{array}$ \\
\hline & & $\begin{array}{l}\text { NCT02413398 } \\
\text { (clinicaltrials.gov) }\end{array}$ & $\begin{array}{l}\text { Decrease from baseline in eGFR is greater with } \\
\text { dapagliflozin than placebo at week } 24 \text { but eGFR return } \\
\text { to baseline levels at week } 27\end{array}$ \\
\hline \multicolumn{4}{|c|}{ Promising drugs in phase III clinical trials } \\
\hline \multirow[t]{2}{*}{ GLP-1 analog } & Liraglutide & Marso et al. [68], 2016 & Lower rate of new onset of persistent \\
\hline & Semaglutide & Marso et al. [70], 2016 & Lower rates of new or deteriorating nephropathy \\
\hline \multirow{4}{*}{$\begin{array}{l}\text { Endothelin-1 } \\
\text { receptor A } \\
\text { antagonist }\end{array}$} & Avosentan & Mann et al. [75], 2010 & Reduce urinary albumin excretion \\
\hline & & & $\begin{array}{l}\text { Terminated early because of excessive cardiovascular } \\
\text { events }\end{array}$ \\
\hline & Atrasentan & de Zeeuw et al. [76], 2014 & Had a proteinuria-lowering effect \\
\hline & & & Terminated early due to the recruitment issue \\
\hline \multirow[t]{6}{*}{ MRA } & $\begin{array}{l}\text { Apararenone } \\
\text { (MT-3995) }\end{array}$ & $\begin{array}{l}\text { NCT02676401 } \\
\text { (clinicaltrials.gov) }\end{array}$ & Ongoing in Japan \\
\hline & Esaxerenone & Kolkhof et al. [78], 2017 & In phase II and III randomized clinical trial \\
\hline & Finerenone & Pitt et al. [79], 2013 & Reduce albuminuria \\
\hline & & Bakris et al. [80], 2015 & Reduce albuminuria in a dose-dependent manner \\
\hline & & $\begin{array}{l}\text { NCT02540993 } \\
\text { (clinicaltrials.gov) }\end{array}$ & Ongoing \\
\hline & & $\begin{array}{l}\text { NCT } 02545049 \\
\text { (clinicaltrials.gov) }\end{array}$ & Ongoing \\
\hline \multirow[t]{6}{*}{$\begin{array}{l}\text { Antifibrotic } \\
\text { therapy }\end{array}$} & \multirow[t]{2}{*}{ Pirfenidone } & Sharma et al. [24], 2011 & $\begin{array}{l}\text { Have an mean increase of eGFR after } 1 \text { year of therapy } \\
\text { in } 1,200 \mathrm{mg} / \mathrm{d}\end{array}$ \\
\hline & & $\begin{array}{l}\text { NCT02689778 } \\
\text { (clinicaltrials.gov) }\end{array}$ & Ongoing \\
\hline & Pentoxifylline & $\begin{array}{l}\text { Navarro-Gonzalez et al. [83], } \\
2015\end{array}$ & $\begin{array}{l}\text { Reduce albuminuria, slow progression of renal disease } \\
\text { in patients with type } 2 \text { diabetes and stages } 3-4 \text { CKD }\end{array}$ \\
\hline & & NCT03625648 & Ongoing \\
\hline & & NCT03664414 & Ongoing \\
\hline & & (clinicaltrials.gov) & \\
\hline
\end{tabular}

Potential drugs required further validations

Anti-AGE drugs Pyridoxamine Williams et al. [84], $2007 \quad$ Not provide a significant renal protection in DKD

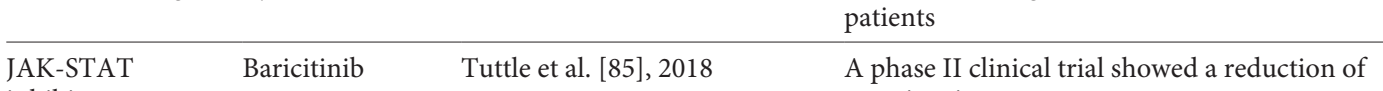

inhibitor $\quad$ proteinuria

\begin{tabular}{llll}
\hline Nrf2 activator & $\begin{array}{l}\text { Bardoxolone } \\
\text { methyl }\end{array}$ & $\begin{array}{l}\text { Pergola et al. [23], 2011 } \\
\text { de Zeeuw et al. [90], 2013 }\end{array}$ & $\begin{array}{l}\text { Have no influence of albuminuria } \\
\text { Increase the GFR in patients with type 2 DM } \\
\text { Phase III clinical study was terminated early because } \\
\text { of more cardiovascular events }\end{array}$ \\
\hline Nox1/4 inhibitor & $\begin{array}{l}\text { GKT137831 } \\
\text { APX-115 }\end{array}$ & $\begin{array}{l}\text { Gorin et al. [92], 2015 } \\
\text { Cha et al. [94], 2017 }\end{array}$ & $\begin{array}{l}\text { A beneficial effect in murine models of DN } \\
\text { A renal protective effect in an experimental animal } \\
\text { model of diabetes }\end{array}$ \\
\hline $\begin{array}{l}\text { Inhibitor of } \\
\text { chemokines } \\
\text { cytokines }\end{array}$ & NOX-E36 & $\begin{array}{l}\text { Boels et al. [95], 2017 } \\
\text { Menne et al. [96], 2017 }\end{array}$ & $\begin{array}{l}\text { A reduction in albuminuria in mouse models } \\
\text { A phase II clinical trial demonstrated a reduced } \\
\text { albuminuria in patients with T2DM and DN }\end{array}$ \\
\hline
\end{tabular}

SGLT2, sodium-glucose co-transporter-2; GLP-1, glucagon-like peptide-1; MRA, mineralocorticoid receptor antagonists; AGE, advanced glycation end products; JAK-STAT, janus kinase/signal transducer and activator of transcription; Nrf2, nuclear factor-2; Nox1/4, NADPH oxidase; DKD, diabetic kidney disease; GFR, glomerular filtration rate; CKD, chronic kidney disease; DN, diabetic nephropathy; T2DM, type 2 diabetes mellitus. 
necessarily correlate with histological changes in DKD patients. Identification of biomarkers for early detection of DKD patients at high risk for progression could help us to better manage DKD patients and prevent their progression. Identification of SGLT2 inhibitors as a new therapy for DKD has a huge impact, however, is not sufficient to halt the progression of DKD. Therefore, there is an urgent need to better understand the pathogenesis of DKD and develop more drugs to treat these patients.

\section{Acknowledgments}

There are no acknowledgments to declare.

\section{Disclosure Statement}

The authors have no conflicts of interest to declare.

\section{Funding Sources}

J.C.H. is supported by VA Merit Award, NIH 1R01DK078897, NIH 1R01DK088541, NIH P01-DK-56492; K.L. is supported by NIH R01 DK117913.

\section{Author Contributions}

Y.C. and J.C.H. wrote the manuscript; K.L. and Z.N. revised manuscript.

\section{References}

1 Karger Publishers [Internet].Centers for Disease Control and Prevention: National Diabetes Statistics Report, 2017 [cited Feb 24, 2018]. Available from: https://www.cdc.gov/diabetes/data/statistics/statistics-report.html.

2 Wang L, Gao P, Zhang M, Huang Z, Zhang D, Deng Q, et al. Prevalence and Ethnic Pattern of Diabetes and Prediabetes in China in 2013. JAMA. 2017 Jun;317(24):2515-23.

3 Zheng Y, Ley SH, Hu FB. Global aetiology and epidemiology of type 2 diabetes mellitus and its complications. Nat Rev Endocrinol. 2018 Feb;14(2):88-98.

4 Valencia WM, Florez H. How to prevent the microvascular complications of type 2 diabetes beyond glucose control. BMJ. 2017 Jan; 356:16505.

5 Burrows NR, Hora I, Geiss LS, Gregg EW, Albright A. Incidence of End-Stage Renal Disease Attributed to Diabetes Among Persons with Diagnosed Diabetes - United States and Puerto Rico, 2000-2014. MMWR Morb Mortal Wkly Rep. 2017 Nov;66(43):1165-70.

6 Zhang L, Zhao MH, Zuo L, Wang Y, Yu F, Zhang H, et al; CK-NET Work Group. China Kidney Disease Network (CK-NET) 2015 Annual Data Report. Kidney Int Suppl (2011). 2019 Mar;9(1):e1-81.

7 Zhang L, Long J, Jiang W, Shi Y, He X, Zhou $Z$, et al. Trends in Chronic Kidney Disease in China. N Engl J Med. 2016 Sep;375(9):905-6.

8 Perkins BA, Ficociello LH, Roshan B, Warram JH, Krolewski AS. In patients with type 1 diabetes and new-onset microalbuminuria the development of advanced chronic kidney disease may not require progression to proteinuria. Kidney Int. 2010 Jan;77(1):57-64.

9 Krolewski AS. Progressive renal decline: the new paradigm of diabetic nephropathy in type 1 diabetes. Diabetes Care. 2015 Jun; 38(6):954-62.
10 Thorn LM, Gordin D, Harjutsalo V, Hägg S, Masar R, Saraheimo M, et al.; FinnDiane Study Group. The Presence and Consequence of Nonalbuminuric Chronic Kidney Disease in Patients With Type 1 Diabetes. Diabetes Care. 2015 Nov;38(11):2128-33.

11 Perkins BA, Ficociello LH, Ostrander BE, Silva $\mathrm{KH}$, Weinberg J, Warram JH, et al. Microalbuminuria and the risk for early progressive renal function decline in type 1 diabetes. J Am Soc Nephrol. 2007 Apr;18(4):1353-61.

12 Rigalleau V, Lasseur C, Raffaitin C, Beauvieux MC, Barthe N, Chauveau P, et al. Normoalbuminuric renal-insufficient diabetic patients: a lower-risk group. Diabetes Care. 2007 Aug; 30(8):2034-9.

13 Macisaac RJ, Jerums G. Diabetic kidney disease with and without albuminuria. Curr Opin Nephrol Hypertens. 2011 May;20(3): 246-57.

14 Solini A, Penno G, Bonora E, Fondelli C, Orsi $\mathrm{E}$, Arosio M, et al.; Renal Insufficiency And Cardiovascular Events (RIACE) Study Group. Diverging association of reduced glomerular filtration rate and albuminuria with coronary and noncoronary events in patients with type 2 diabetes: the renal insufficiency and cardiovascular events (RIACE) Italian multicenter study. Diabetes Care. 2012 Jan; 35(1):143-9.

15 Thomas MC, Brownlee M, Susztak K, Sharma K, Jandeleit-Dahm KA, Zoungas S, et al. Diabetic kidney disease. Nat Rev Dis Primers. 2015 Jul;1(1):15018.

16 Afkarian M, Zelnick LR, Hall YN, Heagerty PJ, Tuttle K, Weiss NS, et al. Clinical Manifestations of Kidney Disease Among US Adults With Diabetes, 1988-2014. JAMA. 2016 Aug; 316(6):602-10.

17 Kramer HJ, Nguyen QD, Curhan G, Hsu CY. Renal insufficiency in the absence of albuminuria and retinopathy among adults with type 2 diabetes mellitus. JAMA. 2003 Jun;289(24): 3273-7.
18 Porrini E, Ruggenenti P, Mogensen CE, Barlovic DP, Praga M, Cruzado JM, et al.; ERAEDTA diabesity working group. Non-proteinuric pathways in loss of renal function in patients with type 2 diabetes. Lancet Diabetes Endocrinol. 2015 May;3(5):382-91.

19 Penno G, Solini A, Zoppini G, Orsi E, Zerbini G, Trevisan R, et al.; Renal Insufficiency And Cardiovascular Events (RIACE) Study Group. Rate and determinants of association between advanced retinopathy and chronic kidney disease in patients with type 2 diabetes: the Renal Insufficiency And Cardiovascular Events (RIACE) Italian multicenter study. Diabetes Care. 2012 Nov;35(11):2317-23.

20 Watkins PJ, Parsons V, Bewick M. The prognosis and management of diabetic nephropathy. Clin Nephrol. 1977 Jun;7(6):243-9.

21 de Boer IH, Sun W, Cleary PA, Lachin JM, Molitch ME, Steffes MW, et al.; DCCT/EDIC Research Group. Intensive diabetes therapy and glomerular filtration rate in type 1 diabetes. N Engl J Med. 2011 Dec;365(25):2366-76.

22 Finne P, Reunanen A, Stenman S, Groop PH, Grönhagen-Riska C. Incidence of end-stage renal disease in patients with type 1 diabetes. JAMA. 2005 Oct;294(14):1782-7.

23 Pergola PE, Raskin P, Toto RD, Meyer CJ, Huff JW, Grossman EB, et al.; BEAM Study Investigators. Bardoxolone methyl and kidney function in CKD with type 2 diabetes. $\mathrm{N}$ Engl J Med. 2011 Jul;365(4):327-36.

24 Sharma K, Ix JH, Mathew AV, Cho M, Pflueger A, Dunn SR, et al. Pirfenidone for diabetic nephropathy. J Am Soc Nephrol. 2011 Jun;22(6):1144-51.

25 Chen JL, Francis J. Pyridoxamine, advanced glycation inhibition, and diabetic nephropathy. J Am Soc Nephrol. 2012 Jan;23(1):6-8.

26 Thakar CV, Christianson A, Himmelfarb J, Leonard AC. Acute kidney injury episodes and chronic kidney disease risk in diabetes mellitus. Clin J Am Soc Nephrol. 2011 Nov; 6(11):2567-72. 
27 Monseu M, Gand E, Saulnier PJ, Ragot S, Piguel X, Zaoui P, et al.; SURDIAGENE Study Group. Acute Kidney Injury Predicts Major Adverse Outcomes in Diabetes: Synergic Impact With Low Glomerular Filtration Rate and Albuminuria. Diabetes Care. 2015 Dec; 38(12):2333-40.

28 Sykes L, Asar O, Ritchie J, Raman M, Vassallo $\mathrm{D}$, Alderson HV, et al. The influence of multiple episodes of acute kidney injury on survival and progression to end stage kidney disease in patients with chronic kidney disease. PLoS One. 2019 Jul;14(7):e0219828.

29 Brancati FL, Whelton PK, Randall BL, Neaton JD, Stamler J, Klag MJ. Risk of end-stage renal disease in diabetes mellitus: a prospective cohort study of men screened for MRFIT. Multiple Risk Factor Intervention Trial. JAMA. 1997 Dec;278(23):2069-74.

30 Lok CE, Oliver MJ, Rothwell DM, Hux JE. The growing volume of diabetes-related dialysis: a population based study. Nephrol Dial Transplant. 2004 Dec;19(12):3098-103.

31 Kanaya AM, Adler N, Moffet HH, Liu J, Schillinger D, Adams A, et al. Heterogeneity of diabetes outcomes among asians and pacific islanders in the US: the diabetes study of northern california (DISTANCE). Diabetes Care. 2011 Apr;34(4):930-7.

32 Huang ES, Laiteerapong N, Liu JY, John PM, Moffet HH, Karter AJ. Rates of complications and mortality in older patients with diabetes mellitus: the diabetes and aging study. JAMA Intern Med. 2014 Feb;174(2):251-8.

33 Helve J, Sund R, Arffman M, Harjutsalo V, Groop PH, Grönhagen-Riska C, et al. Incidence of End-Stage Renal Disease in Patients With Type 1 Diabetes. Diabetes Care. 2018 Mar;41(3):434-9.

34 Finne P, Groop PH, Arffman M, Kervinen M, Helve J, Grönhagen-Riska C, et al. Cumulative Risk of End-Stage Renal Disease Among Patients With Type 2 Diabetes: A Nationwide Inception Cohort Study. Diabetes Care. 2019 Apr;42(4):539-44.

35 Coca SG, Ismail-Beigi F, Haq N, Krumholz HM, Parikh CR. Role of intensive glucose control in development of renal end points in type 2 diabetes mellitus: systematic review and meta-analysis intensive glucose control in type 2 diabetes. Arch Intern Med. 2012 May;172(10):761-9.

36 Zerbini G, Bonfanti R, Meschi F, Bognetti E, Paesano PL, Gianolli L, et al. Persistent renal hypertrophy and faster decline of glomerular filtration rate precede the development of microalbuminuria in type 1 diabetes. Diabetes. 2006 Sep;55(9):2620-5.

37 Nathan DM, Genuth S, Lachin J, Cleary P, Crofford O, Davis M, et al.; Diabetes Control and Complications Trial Research Group. The effect of intensive treatment of diabetes on the development and progression of longterm complications in insulin-dependent diabetes mellitus. N Engl J Med. 1993 Sep; 329(14):977-86.
38 Patel A, MacMahon S, Chalmers J, Neal B, Billot L, Woodward M, et al.; ADVANCE Collaborative Group. Intensive blood glucose control and vascular outcomes in patients with type 2 diabetes. N Engl J Med. 2008 Jun; 358(24):2560-72.

39 Zoungas S, Chalmers J, Ninomiya T, Li Q, Cooper ME, Colagiuri S, et al.; ADVANCE Collaborative Group. Association of HbAlc levels with vascular complications and death in patients with type 2 diabetes: evidence of glycaemic thresholds. Diabetologia. 2012 Mar;55(3):636-43.

40 Fufaa GD, Weil EJ, Lemley KV, Knowler WC, Brosius FC 3rd, Yee B, et al. Structural Predictors of Loss of Renal Function in American Indians with Type 2 Diabetes. Clin J Am Soc Nephrol. 2016 Feb;11(2):254-61.

41 Klessens CQ, Woutman TD, Veraar KA, Zandbergen M, Valk EJ, Rotmans JI, et al. An autopsy study suggests that diabetic nephropathy is underdiagnosed. Kidney Int. 2016 Jul; 90(1):149-56.

42 Pezzolesi MG, Skupien J, Mychaleckyj JC, Warram JH, Krolewski AS. Insights to the genetics of diabetic nephropathy through a genome-wide association study of the GoKinD collection. Semin Nephrol. 2010 Mar;30(2): $126-40$.

43 Jim B, Santos J, Spath F, Cijiang He J. Biomarkers of diabetic nephropathy, the present and the future. Curr Diabetes Rev. 2012 Sep; $8(5): 317-28$.

44 Gohda T, Niewczas MA, Ficociello LH, Walker WH, Skupien J, Rosetti F, et al. Circulating TNF receptors 1 and 2 predict stage 3 CKD in type 1 diabetes. J Am Soc Nephrol. 2012 Mar; 23(3):516-24.

45 Niewczas MA, Gohda T, Skupien J, Smiles AM, Walker WH, Rosetti F, et al. Circulating TNF receptors 1 and 2 predict ESRD in type 2 diabetes. J Am Soc Nephrol. 2012 Mar;23(3): 507-15.

46 Pedigo CE, Ducasa GM, Leclercq F, Sloan A, Mitrofanova A, Hashmi T, et al. Local TNF causes NFATc1-dependent cholesterol-mediated podocyte injury. J Clin Invest. 2016 Sep;126(9):3336-50.

47 Coca SG, Nadkarni GN, Huang Y, Moledina DG, Rao V, Zhang J, et al. Plasma Biomarkers and Kidney Function Decline in Early and Established Diabetic Kidney Disease. J Am Soc Nephrol. 2017 Sep;28(9):2786-93.

48 Badal SS, Danesh FR. New insights into molecular mechanisms of diabetic kidney disease. Am J Kidney Dis. 2014 Feb;63(2 Suppl 2):S63-83.

49 Yu SM, Bonventre JV. Acute Kidney Injury and Progression of Diabetic Kidney Disease. Adv Chronic Kidney Dis. 2018 Mar;25(2): 166-80.

50 Caramori ML, Kim Y, Huang C, Fish AJ, Rich SS, Miller ME, et al. Cellular basis of diabetic nephropathy: 1 . Study design and renal structural-functional relationships in patients with long-standing type 1 diabetes. Diabetes. 2002 Feb;51(2):506-13.
51 Drummond K, Mauer M; International Diabetic Nephropathy Study Group. The early natural history of nephropathy in type 1 diabetes: II. Early renal structural changes in type 1 diabetes. Diabetes. 2002 May;51(5):1580-7.

52 Mauer M, Drummond K; Study Design and Baseline Characteristics of the Study Participants. The early natural history of nephropathy in type 1 diabetes: I. Study design and baseline characteristics of the study participants. Diabetes. 2002 May;51(5):1572-9.

53 Fioretto P, Mauer M. Histopathology of diabetic nephropathy. Semin Nephrol. 2007 Mar; 27(2):195-207.

54 Umanath K, Lewis JB. Update on Diabetic Nephropathy: core Curriculum 2018. Am J Kidney Dis. 2018 Jun;71(6):884-95.

55 Mauer M, Zinman B, Gardiner R, Suissa S, Sinaiko A, Strand T, et al. Renal and retinal effects of enalapril and losartan in type 1 diabetes. N Engl J Med. 2009 Jul;361(1):40-51.

56 Chaturvedi N; The EUCLID Study Group. Randomised placebo-controlled trial of lisinopril in normotensive patients with insulindependent diabetes and normoalbuminuria or microalbuminuria. Lancet. 1997 Jun; 349(9068):1787-92.

57 Bilous R, Chaturvedi N, Sjølie AK, Fuller J, Klein R, Orchard T, et al. Effect of candesar$\tan$ on microalbuminuria and albumin excretion rate in diabetes: three randomized trials. Ann Intern Med. 2009 Jul;151(1):11-20.

58 Fried LF, Emanuele N, Zhang JH, Brophy M, Conner TA, Duckworth W, et al.; VA NEPHRON-D Investigators. Combined angiotensin inhibition for the treatment of diabetic nephropathy. N Engl J Med. 2013 Nov;369(20): 1892-903.

59 Rieg T, Masuda T, Gerasimova M, Mayoux E, Platt K, Powell DR, et al. Increase in SGLT1mediated transport explains renal glucose reabsorption during genetic and pharmacological SGLT2 inhibition in euglycemia. Am J Physiol Renal Physiol. 2014 Jan;306(2):F18893.

60 van Bommel EJ, Muskiet MH, Tonneijck L, Kramer MH, Nieuwdorp M, van Raalte DH. SGLT2 Inhibition in the Diabetic KidneyFrom Mechanisms to Clinical Outcome. Clin J Am Soc Nephrol. 2017 Apr;12(4):700-10.

61 Cherney DZ, Perkins BA, Soleymanlou N, Maione M, Lai V, Lee A, et al. Renal hemodynamic effect of sodium-glucose cotransporter 2 inhibition in patients with type 1 diabetes mellitus. Circulation. 2014 Feb;129(5):58797.

62 UK Prospective Diabetes Study Group. Efficacy of atenolol and captopril in reducing risk of macrovascular and microvascular complications in type 2 diabetes: UKPDS 39. BMJ. 1998 Sep;317(7160):713-20.

63 Wanner C, Inzucchi SE, Zinman B. Empagliflozin and Progression of Kidney Disease in Type 2 Diabetes. N Engl J Med. 2016 Nov; 375(18):1801-2. 
64 Perkovic V, Jardine MJ, Neal B, Bompoint S, Heerspink HJ, Charytan DM, et al.; CREDENCE Trial Investigators. Canagliflozin and Renal Outcomes in Type 2 Diabetes and Nephropathy. N Engl J Med. 2019 Jun; 380(24):2295-306

65 Heerspink HJ, Desai M, Jardine M, Balis D, Meininger G, Perkovic V. Canagliflozin Slows Progression of Renal Function Decline Independently of Glycemic Effects. J Am Soc Nephrol. 2017 Jan;28(1):368-75.

66 Dekkers CC, Petrykiv S, Laverman GD, Cherney DZ, Gansevoort RT, Heerspink HJ. Effects of the SGLT-2 inhibitor dapagliflozin on glomerular and tubular injury markers. Diabetes Obes Metab. 2018 Aug;20(8):1988-93.

67 Fioretto P, Del Prato S, Buse JB, Goldenberg R, Giorgino F, Reyner D, et al.; DERIVE Study Investigators. Efficacy and safety of dapagliflozin in patients with type 2 diabetes and moderate renal impairment (chronic kidney disease stage 3A): the DERIVE Study. Diabetes Obes Metab. 2018 Nov;20(11):2532-40.

68 Marso SP, Daniels GH, Brown-Frandsen K, Kristensen P, Mann JF, Nauck MA, et al.; LEADER Steering Committee; LEADER Trial Investigators. Liraglutide and Cardiovascular Outcomes in Type 2 Diabetes. N Engl J Med. 2016 Jul;375(4):311-22.

69 Mann JF, Ørsted DD, Buse JB. Liraglutide and Renal Outcomes in Type 2 Diabetes. N Engl J Med. 2017 Nov;377(22):2197-8

70 Marso SP, Bain SC, Consoli A, Eliaschewitz FG, Jódar E, Leiter LA, et al.; SUSTAIN-6 Investigators. Semaglutide and Cardiovascular Outcomes in Patients with Type 2 Diabetes. N Engl J Med. 2016 Nov;375(19):1834-44.

71 Groop PH, Cooper ME, Perkovic V, Emser A, Woerle HJ, von Eynatten M. Linagliptin lowers albuminuria on top of recommended standard treatment in patients with type $2 \mathrm{di}$ abetes and renal dysfunction. Diabetes Care. 2013 Nov;36(11):3460-8

72 Mosenzon O, Leibowitz G, Bhatt DL, Cahn A, Hirshberg B, Wei C, et al. Effect of Saxagliptin on Renal Outcomes in the SAVOR-TIMI 53 Trial. Diabetes Care. 2017 Jan;40(1):69-76.

73 Miyazaki Y, Cersosimo E, Triplitt C, DeFronzo RA. Rosiglitazone decreases albuminuria in type 2 diabetic patients. Kidney Int. 2007 Dec;72(11):1367-73.

74 Agarwal R, Saha C, Battiwala M, Vasavada N, Curley T, Chase SD, et al. A pilot randomized controlled trial of renal protection with pioglitazone in diabetic nephropathy. Kidney Int. 2005 Jul;68(1):285-92.

75 Mann JF, Green D, Jamerson K, Ruilope LM, Kuranoff SJ, Littke T, et al.; ASCEND Study Group. Avosentan for overt diabetic nephropathy. J Am Soc Nephrol. 2010 Mar; 21(3):527-35.

76 de Zeeuw D, Coll B, Andress D, Brennan JJ, Tang H, Houser M, et al. The endothelin an- tagonist atrasentan lowers residual albuminuria in patients with type 2 diabetic nephropathy. J Am Soc Nephrol. 2014 May;25(5): 1083-93.

77 Hermidorff MM, de Assis LV, Isoldi MC. Genomic and rapid effects of aldosterone: what we know and do not know thus far. Heart Fail Rev. 2017 Jan;22(1):65-89.

78 Kolkhof P, Bärfacker L. 30 years of the mineralocorticoid receptor: Mineralocorticoid receptor antagonists: 60 years of research and development. J Endocrinol. 2017 Jul; 234(1):T125-40.

79 Pitt B, Kober L, Ponikowski P, Gheorghiade M, Filippatos G, Krum H, et al. Safety and tolerability of the novel non-steroidal mineralocorticoid receptor antagonist BAY 94-8862 in patients with chronic heart failure and mild or moderate chronic kidney disease: a randomized, double-blind trial. Eur Heart J. 2013 Aug;34(31):2453-63.

80 Bakris GL, Agarwal R, Chan JC, Cooper ME, Gansevoort RT, Haller H, et al.; Mineralocorticoid Receptor Antagonist Tolerability Study-Diabetic Nephropathy (ARTS-DN) Study Group. Effect of Finerenone on Albuminuria in Patients With Diabetic Nephropathy: A Randomized Clinical Trial. JAMA. 2015 Sep;314(9):884-94.

81 Mahfoud F, Böhm M, Rump LC, Vonend O, Schmieder RE, Kintscher U. Catheter-based renal nerve ablation and centrally generated sympathetic activity in difficult-to-control hypertensive patients: prospective case series. Hypertension. 2013 Feb;61(2):e17

82 Schlaich M, Hering D, Lambert G, Lambert E, Esler M. Blood pressure and sympathetic nervous system response to renal denervation. Hypertension. 2013 Feb;61(2):e13.

83 Navarro-González JF, Mora-Fernández C, Muros de Fuentes M, Chahin J, Méndez ML, Gallego E, et al. Effect of pentoxifylline on renal function and urinary albumin excretion in patients with diabetic kidney disease: the PREDIAN trial. J Am Soc Nephrol. 2015 Jan; 26(1):220-9.

84 Williams ME, Bolton WK, Khalifah RG, Degenhardt TP, Schotzinger RJ, McGill JB. Effects of pyridoxamine in combined phase 2 studies of patients with type 1 and type 2 diabetes and overt nephropathy. Am J Nephrol. 2007;27(6):605-14.

85 Tuttle KR, Brosius FC 3rd, Adler SG, Kretzler M, Mehta RL, Tumlin JA, et al. JAK1/JAK2 inhibition by baricitinib in diabetic kidney disease: results from a Phase 2 randomized controlled clinical trial. Nephrol Dial Transplant. 2018 Nov;33(11):1950-9.

86 Toth-Manikowski S, Atta MG. Diabetic Kidney Disease: Pathophysiology and Therapeutic Targets. J Diabetes Res. 2015;2015:697010.

87 Cui W, Min X, Xu X, Du B, Luo P. Role of Nuclear Factor Erythroid 2-Related Factor 2 in Diabetic Nephropathy. J Diabetes Res. 2017;2017:3797802.

88 Lazaro I, Lopez-Sanz L, Bernal S, Oguiza A, Recio C, Melgar A, et al. Nrf2 Activation Provides Atheroprotection in Diabetic Mice Through Concerted Upregulation of Antioxidant, Anti-inflammatory, and Autophagy Mechanisms. Front Pharmacol. 2018 Jul;9: 819

89 Zheng H, Whitman SA, Wu W, Wondrak GT, Wong PK, Fang D, et al. Therapeutic potential of Nrf2 activators in streptozotocin-induced diabetic nephropathy. Diabetes. 2011 Nov; 60(11):3055-66.

90 de Zeeuw D, Akizawa T, Audhya P, Bakris GL, Chin M, Christ-Schmidt H, et al.; BEACON Trial Investigators. Bardoxolone methyl in type 2 diabetes and stage 4 chronic kidney disease. N Engl J Med. 2013 Dec;369(26):2492503.

91 Gnudi L, Gentile G, Ruggenenti P. The Patient with Diabetes Mellitus. In: Turner N, Lamiere N, Goldsmith DJ, Wineearls CG, Himmelfarb J, Remuzzi G, editors. Oxford Textbook of Clinical Nephrology. Volume 2. Oxford, UK: Oxford University Press; 2016. pp. 1199-247.

92 Gorin Y, Cavaglieri RC, Khazim K, Lee DY, Bruno F, Thakur S, et al. Targeting NADPH oxidase with a novel dual Nox1/Nox4 inhibitor attenuates renal pathology in type 1 diabetes. Am J Physiol Renal Physiol. 2015 Jun; 308(11):F1276-87.

93 Karger Publishers [Internet]. Business wire: Genkyotex Announces top-line results of phase 2 clinical program [cited Sep 9, 2015]. Available from: https://www.businesswire. com/news/home/20150909005080/en/Genkyotex-Announces-Top-Line-Results-Phase2-Clinical.

94 Cha JJ, Min HS, Kim KT, Kim JE, Ghee JY, Kim HW, et al. APX-115, a first-in-class panNADPH oxidase (Nox) inhibitor, protects $\mathrm{db} / \mathrm{db}$ mice from renal injury. Lab Invest. 2017 Apr;97(4):419-31.

95 Boels MG, Koudijs A, Avramut MC, Sol WM, Wang G, van Oeveren-Rietdijk AM, et al. Systemic Monocyte Chemotactic Protein-1 Inhibition Modifies Renal Macrophages and Restores Glomerular Endothelial Glycocalyx and Barrier Function in Diabetic Nephropathy. Am J Pathol. 2017 Nov; 187(11):2430-40.

96 Menne J, Eulberg D, Beyer D, Baumann M, Saudek F, Valkusz Z, et al.; Emapticap Study Group. C-C motif-ligand 2 inhibition with emapticap pegol (NOX-E36) in type 2 diabetic patients with albuminuria. Nephrol Dial Transplant. 2017 Feb;32(2):307-15.

97 Pedigo CE, Ducasa GM, Leclercq F, Sloan A, Mitrofanova A, Hashmi T, et al. Local TNF causes NFATc1-dependent cholesterol-mediated podocyte injury. J Clin Invest. 2016 Sep;126(9):3336-50. 